\title{
Service requirement for terminal delivery: An empirical study from the perspective of online shoppers
}

\author{
Junjie Xu, Ling Jiang, Yiliang Li \\ Economics \& Management School, Anqing Normal University (China) \\ Xu0926@gmail.com,jiangling0409@,163.com,yiliangli@,126.com
}

Received: May 2013

Accepted: October 2013

\section{Abstract:}

Purpose Terminal delivery made great influences on customer's overall logistics experience in ecommerce situations, while researches for this delivery process lagged far behind in recently years. This work was dedicated to establish a measurement model of terminal delivery in express industry, it contributed to reveal the connotation of the last mile problem and to find out customer's primary requirements in a theoretical views. In addition to that the research would also provide some management implications to related firms as well as government departments.

Design/mathoddogy/approadr Mixed approaches were adopted to achieve the above objective. Firstly the paper carried out systematic literature reviews and several potential dimensions were defined in qualitative analysis, subsequently an empirical study was implemented which included both exploratory factor analysis and confirmatory factor analysis. This quantitative analysis was aimed at verifying theoretical measurement dimensions and even refining their items.

Findings: Four service requirement dimensions including service attitude, service reliability, service standardization and service flexibility were proposed in this work with totally 18 measurement items. The empirical result was significantly different from traditional models of logistics service quality which usually put emphases on the whole transport. Additionally the 
research indicated that online shoppers were more concerned about service process than its result, so process regulation should be strengthened to enhance customer's satisfaction.

Originality/value The research was conducted from the perspective of online shoppers instead of service provider, meanwhile the proposed measurement model focused on terminal delivery rather than overall distribution process, the management implications were useful for related companies or industry administrative department to improve delivery guidance.

Keywards: terminal delivery; service requirement; logistics service quality, delivery management

\section{Introduction}

Parcel delivery was a key implementation stage for e-commerce logistics in the last mile, and it was critical for customer's perception of logistics service quality. According to the regularly reports of consumers' complaints issued by State Post Bureau of the People's Republic of China, delivery service always ranked second position only to parcel delay. In 2011 its proportion in all complaints reached $19.9 \%$, but in the next year the figure continually increased to $27.3 \%$, so it was quite important to pay attention to terminal delivery service. In China, express industry had long been put emphasis on collection and many related enterprises were lack of motivations to supervise delivery quality. Since the construction of delivery specification lagged behind, it was not easy to protect consignee's rights and interests in real circumstance (Tang \& Li, 2009). Although the National Standard of Express Service (GB/T 27917.3-2011) had been launched in 2012, there were only few aspects discussed in this guidance such as delivery time, staff dress, delivery frequency and inspection process, while communication or security mechanism for delivery service did not be included. So the national standard definitely brought out limited effects in practice.

Online shoppers might have multiple expectations for parcel delivery service, investigation of their requirement structure was a prerequisite for establishing and optimizing delivery service specification. However academic studies on terminal delivery were insufficient as most scholars had centered on the whole distribution from consignor to consignee. Moreover, service quality was always the main concept within the area of logistics management in the past thirty years, but service requirement from customer's perspective had been ignored especially in ecommerce circumstance. From the practice of management, service quality assessment was generally completed with service facts while service requirement described customer's prospective imagination, hence measurement dimensions of service quality were probably not consistent with those of service requirement. On the other hand the relation between these two concepts was so affinitive that there were inevitably considerable overlap in terms of measurement dimensions, in certain situation they were even hardly distinguished from each 
other. It was obvious that researches about logistics service quality could provide useful theoretical references for the investigation of customer's delivery requirement.

The paper took the delivery of e-commerce parcels as the research background. In the first stage, five potential measurement dimensions would be suggested through a systematic literature reviews. Then a questionnaire survey would be conducted to extract the final measurement model based on data analysis. After that the paper intended to discuss some management implications in order to improve terminal delivery service in express industry. The reason for taking e-commerce logistics as the research scenario was that parcels derived from online shopping accounted for $60 \%$ in express industry of China, so e-commerce represented a typical delivery situation. Meanwhile it was more convenient to carry out the survey to individual e-buyers with low cost than the counterparts. We also speculated that there were some differences on customer's service requirement structure between e-commerce and traditional business, so this paper would focus on the former circumstance.

\section{Literature reviews}

Studies about logistics service consisted of concept definition, measurement methodology and theoretical discussion in sequence (Zheng, Dong \& Jin, 2007), related papers on dimensions of service quality were particularly rich which could be divided into two fields, one was traditional logistics and the other was e-commerce logistics. A brief reviews was given as follows:

\subsection{Traditional logistics}

Zheng, Dong and Jin (2008) summarized a lot of related works in detail, they claimed that most of the former studies were implemented from the perspective of logistics provider including the well-known 7Rs theory proposed by Perrault. As the research trend turned to customer's view, more and more scholars put their emphases on this field. Parasuraman, Zeithaml and Berry (1988) developed SERVQUAL which was regarded as a symbolic measurement tool, there were five dimensions in SERVQUAL including tangibles, reliability, responsiveness, assurance and empathy, and this measurement scale had been adopted directly in logistics industry (Liu, Gong \& Yang, 2006; Cui \& Zhang, 2010). However, there were still much controversies about the applicability of SERVQUAL because the discrepancy of service connotation among different industries was always ignored. For example, Xu (2009) carried out an empirical study based on the original 22 items and finally extracted only three dimensions which were named customized timeliness, resource normalization and attitude respectively, so it was necessary to design the measurement scale based on the characteristics of logistics service.

Mentzer, Gomes and Krapf (1989) toke both physical distribution and marketing as the contents of logistics service, they proposed the Physical Distribution Service Quality (PDSQ) consisted of timeliness, availability and quality. Their theoretical framework was indirectly supported by the empirical test of Bienstock, Mentzer and Bird (1997), the latter article put 
forward three dimensions of timeliness, availability and condition. As it was hard to completely separate the logistics from commercial issues, physical distribution in a narrow sense could not represented the whole contents of logistics, so research by Mentzer Flint and Kent (1999) combined physical distribution with customer service and presented the famous measurement scale of Logistics Service Quality (LSQ). The scale was comprised of nine dimensions including personal contact quality, order release quality, information quality, order procedure, order accuracy, order condition, order quality, order discrepancy handling and timeliness, most papers published in later years would definitely refer to this significant work. It was evident that nine-dimension model was not yet a perfect solution if applied in certain situations due to distinctions in culture or industry (Mentzer \& Williams, 2001), consequently it was necessary to deal with service quality in concrete circumstance. For example, research by Zheng, Jin, Dong and Liu (2007) brought forward seven dimensions including timeliness, personal contact, order fulfillment, discrepancy handling, flexibility, order condition and convenience when handling local measurement scale in China, their contributions to logistics service quality were more suitable for comprehensions of the majority of Chinese. Zhang and Wu (2007) also proposed timeliness, reliability, flexibility, security and economics to describe logistics service, they even called the former four dimensions as functional characteristics and the last dimension was named economical characteristics.

Some scholars tried to set up a hierarchical measurement scheme to overcome the shortcomings of overmuch dimensions. Stank, Goldsby, Vickery and Savitskie (2003) divided logistics service quality into operational, relational and cost performance, the former referred to timeliness, reliability and accuracy, the middle contained responsiveness, assurance and empathy, the latter was similar to ordinary cost concept. Research by Ye, Cai, Ye and Dai (2011) combined the ideas of Mentzer and Williams (2001) and Stank et al. (2003), they proposed three dimensions to describe logistics service quality including operational, interactive and cost quality. Operational quality contained information quality, timeliness, reliability, discrepancy handling, service district, accuracy and convenience. Interactive quality comprised professional specialization, service attitude, requirement acquaintance, customer care and responsibility. The meaning of cost quality was equal to the whole price, relative price and expected price. As for most hierarchical measurement models, there were indeed a lot of innovations in the matter of theoretical viewpoint, but their logical structures were also more complicated than the counterparts, and it was believed to be the primary restriction for the application of hierarchical models.

Additionally, several papers set up measurement models through process analysis or capability analysis. Li, Peng and Huang (2007) investigated service perception of customers to 3PL (Third Party Logistics) based on potential quality, hard process quality, soft process quality and output quality. Lin (2009) focused on tangibles, business handling, service providing, business development and overall image. Zhou and Shi (2009) proposed a simple model including service performance, service process and service capability. 


\subsection{E-commerce logistics}

Most literatures regarding e-commerce logistics were published in recent ten years. Xing and Grant (2006) compared delivery service between online retailer and multi-channel retailer, they put emphases on availability, timeliness, condition and return service. Feng, Zheng and Tan (2007) tried to establish a representative measurement scheme, they explored timeliness, personal contact quality, order quality, discrepancy handling, operation normalization and convenience. Zheng (2008) proposed a systematic reviews in her doctoral dissertation, there were five dimensions in her scale which involved order quality, customization service quality, response quality, delivery quality and order discrepancy handling quality. Bian, Ju, Xu \& Ding (2011) concentrated on seven particular items in their article with regard to logistics service perception but they did not extract any dimensions. Furthermore, Huang and Wang (2011) amended Mentzer's nine-dimension scale, they deleted order quality according to the distinguishing feature of online shopping and eventually remained eight dimensions. Zhang, Xie and Chen (2013) defined 38 customer touch points with the methodology of process analysis, they established a six-dimension model such as delivery service level, accepting order service level, accurate fulfilling order ability and so on. In the whole, there was a growing number of studies involving e-commerce logistics, however, few of them focused on terminal delivery stage, so it was still a valuable exploration task to investigate the service requirement of online shoppers for parcel delivery in the last mile.

\section{Potential measurement dimensions}

Based on the above literatures, we initially extracted five potential dimensions for terminal delivery service:

\subsection{Reliability}

The meaning of reliability involved both accuracy and security. On the one hand, accuracy had long been treated as a basic expectation for express service, a lot of articles had taken accuracy into their proposed models (Mentzer \& Williams, 2001; Stank, Goldsby et al., 2003; Zhang et al., 2013). Under the situation of the whole logistics service process, accuracy was generally interpreted as the consistence between order and the actual goods. But in the delivery process, accuracy requirement implied no mistake such as delivering the wrong parcel to customers, meanwhile the courier was also anticipated to keep the promise of the delivery time. On the other hand, express enterprises should give guarantees to their customers that parcels would be in good condition during the delivery process. In the past few years, a lot of incidents about rough sorting or loss of goods had been reported, online shoppers were more anxious for the security of their goods than before, so they definitely expected that there was no stealing or rough handling behaviors. 


\subsection{Timeliness}

Timeliness was already included in many articles (Mentzer et al., 1999; Feng et al., 2007), this requirement reflected that customers wanted to boost the efficiency of handling process. Considering the characteristic of terminal delivery, we deemed that timeliness was an indispensable part for customer's service requirement. Couriers usually undertook dual responsibilities of collection and delivery, driven by interests, they would give priority to parcel collection for the arrangement of working time, so most couriers would not carry out multidelivery to customers in their travelling routines and that was the fundamental reason for parcel delay in local depot. The desire for timeliness could be resolved into three aspects, firstly when the parcel arrived at terminal depot, it should be delivered to the destination immediately, secondly the parcel should be delivered in accordance with service specification even in a busy day, thirdly the waiting time should be brief and acceptable from telephone inquiry to signing for the parcels.

\subsection{Personal contact}

As discussed in previous section, some scholars had taken personal contact as one of the dimensions of logistics service quality(Stank et al., 2003). A bad contact performance would definitely worsen customer's delivery experience and even aggravate contradictions for other service defects. In contrast, a good contact contributed to the elimination of customer's complaint and it was expected to improve the degree of delivery service satisfaction. So personal contact was indeed a multiplication factor for customer's service experience. There were at least six different implications for personal contact. Firstly, couriers should be patient and polite during the communication with the client. Secondly, if there was any damage or delay in the delivery process, couriers were looked forward to apologize on behalf of express enterprise for the incident. Thirdly, couriers could not prevent customer's decision of rejection or return of the damaged parcels, in other words reasonable claims of their customers should be respected. Fourthly, couriers were expected to call their customers before carrying out home delivery, they should positively avoid the failure of delivery. Fifthly, couriers should be willing to accept inquiries from customers and carefully deal with any complaints. Furthermore, convenient communication channels were also regarded as a basic precondition for personal contact, it asked for an open and precise publishing mechanism for the contact approaches issued by express enterprise.

\subsection{Operation behavior}

Delivery operation according to the right specification was a guarantee for express enterprises to enhance their service level, it was believed that appropriate operation behavior would indirectly strengthen the loyalties of express customers. Although most researches had not focused on operational performance yet, similar measurement items did be utilized in certain scales (Zhang et al., 2013). As everyone knew, staff training of private express enterprise was not sufficient, the couriers often violated regulations of delivery operation and sometimes even 
led to potential offence to their customers. By analysis of common complaints in express industry, we concluded four kinds of service requirements concerning operational behavior. Firstly, couriers should cooperate with their customers to check suspicious parcels and provide guidance for customers' rejection or returning decisions. Secondly, if couriers were going to entrust someone to sign for the parcels, they were expected to inform the owners in time, and this demand was to protect customers' rights of know. Thirdly, the courier should offer to require signature for the delivery and at last the courier was also expected to verify the identification of customers in an appropriate way to avoid falsely claiming risks.

\subsection{Flexibility}

Flexible service meant that couriers were expected to deliver parcels in customized time or place if possible. It probably exceeded service obligation in the contracts in most circumstances. From the point of customers, flexible delivery was always regarded one of the important dimensions for logistics service quality and it was usually interpreted as the following two characteristics. On the one hand, if customers hoped to change the delivery arrangement in advance, couriers were supposed to meet the requirements. On the other hand, couriers were anticipated to perform redelivery if failed in the first attempts. According to the National Standard of Express Service in China, related companies should provide twice free home deliveries to their customers, however the actual implementation was unoptimistic, redelivery was a common expectation especially for full-time workers.

\section{Empirical analysis}

\subsection{Questionnaire survey}

With the above discussions, measurement items of every dimension were independently compiled by three teachers with rich online shopping experience, and then were initially summarized into 41 alternative items. Two professors engaging in management research were invited to carry out checks and evaluations, and finally 27 measurement items were screened out. In order to unify language expressions, all measurement items were compiled in forms like "I hope..." or "deliverers should...". 20 college students were recruited by the research group to take language evaluation so as to see whether the items were presented clearly.

The questionnaire consisted of two parts: the first part was customer service requirement scale in which each item was numbered in a random order (T1 T27), and was measured using Likert five point scale ( 1 stands for strong disagreement, 5 stands for strong agreement); In the second part, personal information and feedbacks were collected such as gender, age and network age et al.. The research group firstly conducted a small-scale pre-survey in university campus and through analysis, the quality of the questionnaire proved to be acceptable. During the period from December 2012 to March 2013, the research group organized formal investigation via 56 online shops at Taobao.com and totally recruited 642 e-buyers to answer 
online questionnaire. Taking into consideration the possibilities of randomly submitting online questionnaire, the research group deleted suspicious questionnaires which consumed excessively short time through questionnaire management system. At the same time, the questionnaire set four resurveyed items to eliminate a few questionnaires through comparing the two answers to see whether they are consistent. Finally, 80 suspicious questionnaires were detected and 562 questionnaires were remained, constituting $87.5 \%$ of all the questionnaires.

In the remaining questionnaires, there were 277 male respondents, accounting for $49.3 \%$ while 285 respondents were female, accounting for $50.7 \%$, which brought balance to sex ratio. Respondents born in the 1960 s were all together 40 , taking up $7.1 \%$ of all respondents. There were 114 respondents born in the 1970s, accounting for $20.3 \%$. Respondents born in the 1980 s were 342 , constituting $60.7 \%$. Those who were born in the 1990 s were 66 , accounting for $11.7 \%$. Generally speaking, people in the seventies and eighties constituted $81.0 \%$. Respondents in this age group were those married who have independent economic capability and permanent residence and they often preferred family consignee address. Next, all valid questionnaires were divided into two groups in accordance with their serial number. The samples of the first group were used for exploratory factor analysis while the samples of the second group were utilized for confirmatory factor analysis, thus achieving cross checks.

\subsection{Construction of measurement model}

\subsubsection{Item analysis}

The samples of the first group were guided into SPSS15.0, and independent-sample T test was conducted on high-low grouping (critical point 27\%) to ensure that all items have good discrimination. According to scale design theory, there should be notable correlation between items and total points. Pearson's correlation coefficient between the initial items and the total points of the scale were studied as indicated in Table 1. All related coefficients reached significance level of 0.05 , indicating that the items had good resolution capability. Since the related coefficients of T1, $\mathrm{T} 2, \mathrm{~T} 13, \mathrm{~T} 20$ and T24 did not surpass 0.4 , they were deleted in the following analysis.

\begin{tabular}{|c|c|c|c|c|c|c|c|}
\hline Item & Coefficients & Item & Coefficients & Item & Coefficients & Item & Coefficients \\
\hline T1 & $\underline{0.312 * *}$ & $\mathrm{~T} 8$ & $0.600 * *$ & $\mathrm{~T} 15$ & $0.600 * *$ & $\mathrm{~T} 22$ & $0.594 * *$ \\
\hline $\mathrm{T} 2$ & $\underline{0.271 * *}$ & $\mathrm{~T} 9$ & $0.610 * *$ & $\mathrm{~T} 16$ & $0.599 * *$ & $\mathrm{~T} 23$ & $0.652 * *$ \\
\hline $\mathrm{T} 3$ & $0.533 * *$ & $\mathrm{~T} 10$ & $0.619 * *$ & $\mathrm{~T} 17$ & $0.571 * *$ & $\mathrm{~T} 24$ & $\underline{0.279 * *}$ \\
\hline $\mathrm{T} 4$ & $0.625 * *$ & $\mathrm{~T} 11$ & $0.666 * *$ & $\mathrm{~T} 18$ & $0.623 * *$ & $\mathrm{~T} 25$ & $0.492 * *$ \\
\hline $\mathrm{T} 5$ & $0.532 * *$ & $\mathrm{~T} 12$ & $0.647 * *$ & $\mathrm{~T} 19$ & $0.648 * *$ & $\mathrm{~T} 26$ & $0.534 * *$ \\
\hline T6 & $0.714 * *$ & $\mathrm{~T} 13$ & $\underline{0.379 * *}$ & $\mathrm{~T} 20$ & $\underline{0.344 * *}$ & $\mathrm{~T} 27$ & $0.489 * *$ \\
\hline $\mathrm{T} 7$ & $0.533 * *$ & $\mathrm{~T} 14$ & $0.649 * *$ & $\mathrm{~T} 21$ & $0.571 * *$ & & \\
\hline
\end{tabular}

Note: $* * \mathrm{p}<0.05$; items with underline coefficients would be deleted.

Table 1. Correlation coefficients between item and the total points of the scale 


\subsubsection{Exploratory factor analysis}

As what mentioned before, five measurement dimensions with relevant items were initially determined from theoretical level but whether the model was scientific and reasonable still remained to be discovered. It was necessary to reconstruct analysis dimension of customer service requirement based on existing measurement items through exploratory factor analysis. Factor extraction applied principal components method and factor rotation applied Varimax. The initial results indicated that factor analysis could be carried out but the communalities of T5, T7, T9, T10, T15 and T21 failed to reach 0.5. Firstly, T15 and T21 with the lowest communalities were tentatively deleted and then T7 and T10 were also deleted according to the results of retests. The remaining 18 measurement items went through factor analysis again. As indicated by the result, KMO measure of sampling adequacy equaled to 0.915 , chisquare value of sphericity test was 1743.768 , significance level was under 0.001 and the communalities of all items surpassed 0.5. The analysis of eigenvalue and variance explained indicated that four eigenvalue were greater than 1 and their cumulative variance contribution rate reached $78.739 \%$ (Table 2 ). The check of factor matrix showed that all factor loadings surpassed 0.5 and the number of items contained in four components was no less than 3 , these results indicated that the extraction process was acceptable.

\begin{tabular}{|c|c|c|c|c|c|c|}
\hline \multirow{2}{*}{ Component } & \multicolumn{3}{|c|}{ Initial eigenvalues } & \multicolumn{2}{c|}{ Extraction sums of squared loadings } \\
\cline { 2 - 7 } & Total & $\%$ of variance & Cumulative \% & Total & $\%$ of variance & Cumulative \% \\
\hline 1 & 6.841 & 38.006 & 38.006 & 4.407 & 24.483 & 24.483 \\
\hline 2 & 3.651 & 20.283 & 58.289 & 4.179 & 23.217 & 47.700 \\
\hline 3 & 2.664 & 14.800 & 73.089 & 3.754 & 20.856 & 68.556 \\
\hline 4 & 1.017 & 5.650 & 78.739 & 1.833 & 10.183 & 78.739 \\
\hline
\end{tabular}

Table 2. Total variance explained

Due to the number of extracted dimensions of exploratory factor analysis was below theoretical expectation, five components were extracted regularly. The results of sphericity test remained unchanged and the communalities of all items stayed at appropriate level. Cumulative variance contribution rate increased slightly but the maximum factor loading of T22 was lower than 0.5 leading to its related component only contained two items $(T 25, T 27)$ which should be deleted together with the component according to the research convention. This had deficiency in theoretical value. Based on scree plot, four components were kept unchanged and named in line with the features of actually contained measurement items (Table 3 ).

\begin{tabular}{|l|l|l|}
\hline \multicolumn{1}{|c|}{ Final dimension } & \multicolumn{1}{c|}{ Measurement item } & \multicolumn{1}{c|}{ Initial dimension } \\
\hline & T12 be polite if contacting with customer & Personal contact \\
& T16 never prevent the decision of rejection & Personal contact \\
Service attitude & T17 be willing to answer the inquiries & Personal contact \\
& T18 be willing to check damaged parcel & Operation behavior \\
& T19 treat the inquiries/complaints seriously & Personal contact \\
& T23 provide guidance for possible rejection & Operation behavior \\
\hline
\end{tabular}




\begin{tabular}{|c|c|c|}
\hline Final dimension & Measurement item & Initial dimension \\
\hline Service reliability & $\begin{array}{l}\text { T3 will not lose customer's parcel } \\
\text { T4 no delay even in busy time } \\
\text { T5 always deliver to the right address } \\
\text { T6 take care of customer's parcel } \\
\text { T8 never steal customer's goods } \\
\text { T9 deliver once the parcel reaching depot }\end{array}$ & $\begin{array}{l}\text { Reliability } \\
\text { Timeliness } \\
\text { Reliability } \\
\text { Reliability } \\
\text { Reliability } \\
\text { Timeliness }\end{array}$ \\
\hline $\begin{array}{l}\text { Service } \\
\text { standardization }\end{array}$ & $\begin{array}{l}\text { T11 dealing with the parcels carefully } \\
\text { T14 duly apologize for all incidents } \\
\text { T26 verify customer's identity }\end{array}$ & $\begin{array}{l}\text { Reliability } \\
\text { Personal contact } \\
\text { Operation behavior }\end{array}$ \\
\hline Service flexibility & $\begin{array}{l}\text { T22 be willing to change delivery time } \\
\text { T25 be willing to change delivery address } \\
\text { T27 provide twice free home delivery }\end{array}$ & $\begin{array}{l}\text { Flexibility } \\
\text { Flexibility } \\
\text { Flexibility }\end{array}$ \\
\hline
\end{tabular}

Table 3. Common factors and measurement items

\subsubsection{Reliability and validity test}

Cronbach' a coefficient of each common factor surpassed 0.7 (Table 4) and total reliability of scale was 0.889 , indicating that internal reliability was good. The scale design conformed to standardized procedures with necessary item screening mechanism put in place, which could ensure content validity of the scale. Low correlation remained between common factors but the correlation between common factor and total point of items was high (significance level was 0.01 ), indicating that the scale had fairly good constructing validity.

\begin{tabular}{|l|c|c|c|c|}
\hline \multicolumn{1}{|c|}{ Dimension } & Service attitude & Service reliability & Service standardization & Service flexibility \\
\hline Cronbach's a & 0.835 & 0.813 & 0.718 & 0.730 \\
\hline Correlation with total point & 0.874 & 0.823 & 0.806 & 0.714 \\
\hline
\end{tabular}

Table 4. Results of reliability and validity test

\subsection{Validation of the theoretical model}

A measurement model of delivery service requirement was constructed with AMOS20.0 and then applied on another group of survey samples, maximum likelihood method was utilized to estimate regression coefficients as well as measuring errors. The model was converged and identified as expected. Standard estimated value was shown in Figure 1 and model fitness was examined from three aspects in this paper.

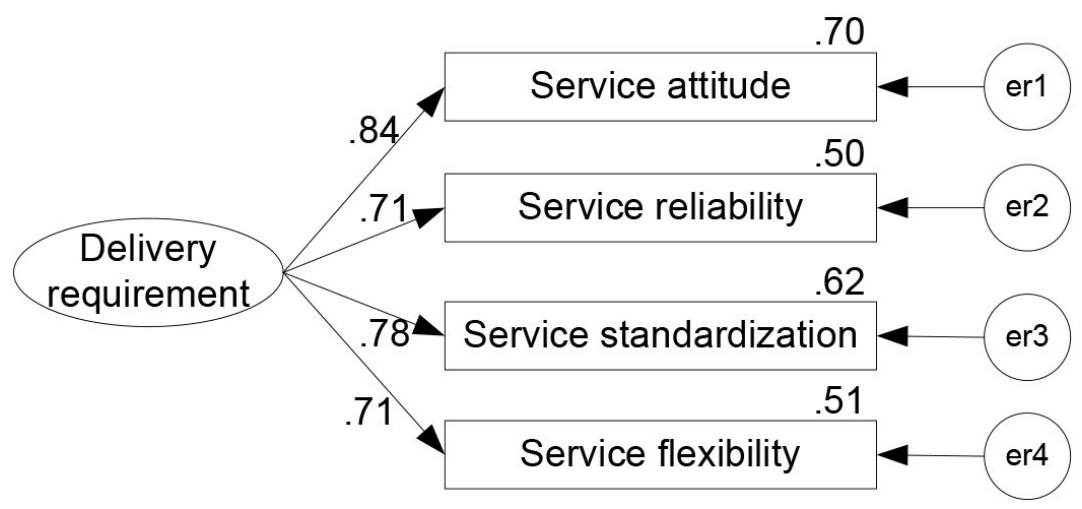

Figure 1. Delivery service requirement of confirmatory factor analysis 
(1) Basic fitness of the model: All error variations reached anticipated significance level with no negative value. Factor loadings of the four observed variables were between 0.71 and 0.84 and there were no excessively large standard errors, it implicated that fitness was fairly good.

(2) Overall fitness of the model: chi-square test value was 3.839, $p=0.147>0.05$, demonstrating that theoretical model conformed to sample data; most indicators such as GFI and RMSEA reached fitness standard (Table 5), it shown that overall fitness of the model was considered fine.

\begin{tabular}{|c|c|c|r|r|c|c|c|}
\hline Indicator & GFI & AGFI & \multicolumn{1}{c|}{ RMR } & RMSEA & CFI & TLI & NC \\
\hline Value & 0.994 & 0.971 & 0.109 & 0.05 & 0.997 & 0.991 & 1.919 \\
\hline Criterion & $>0.90$ & $>0.90$ & $<0.05$ & $<0.08$ & $>0.90$ & $>0.90$ & $1<\mathrm{NC}<3$ \\
\hline Evaluation & fitting & fitting & unfitting & fitting & fitting & fitting & fitting \\
\hline
\end{tabular}

Table 5. Evaluation of primary indicators for the overall fitness

(3) Inner structure fitness of the model: all factor loadings were not lower than 0.71 indicating that observed variables had good reliability. Through calculating, the composite reliability of latent variable (delivery requirement) reached $0.85>0.6$ and average variance extracted (AVE) reached $0.58>0.5$ indicating that all observed variables had high internal relation. All factor loadings of the observed variables passed significance test, meaning that they effectively reflected latent variables. That was to say the proposed measurement model had good validity evidence. Therefore, the fitness of the inner structure of measurement model was proved fine.

Based on the above judgment results, it could be believed that theoretical model and observed data had good fitness, in other words measurement dimension was divided appropriately.

\section{Management implications}

According to the proposed measurement model, service requirement of online shoppers on courier' terminal delivery centered on four aspects covering service attitude, service reliability, service standardization and service flexibility, which was different from studies related to the whole logistics service process. Generally speaking, service reliability mainly referred to the service result, while the rest three dimensions focused on the service process (Figure 2 ), so it was quite obvious that online shoppers had more requirements on process than its result; therefore, process regulation should be strengthened in delivery management.

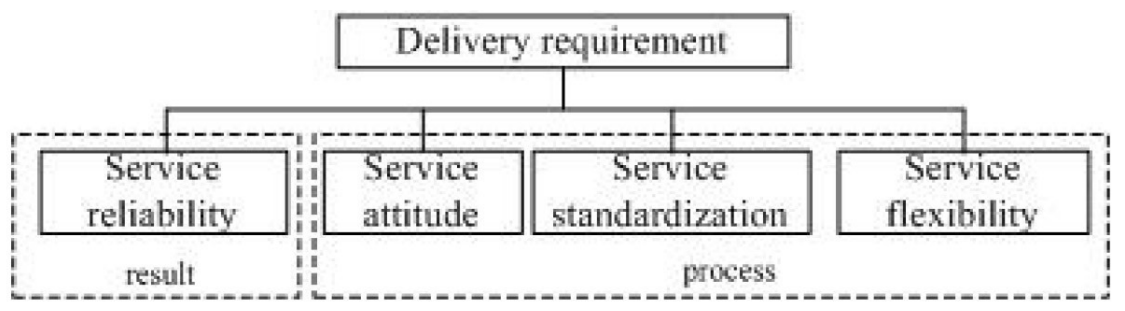

Figure 2. Classification of service requirement dimensions 
As demonstrated in this study, online shoppers in China attached great importance to courier's service attitude (factor loadings in this dimension was the largest), and especially expected that the courier could listen to customers' suggestions in abnormal situations (such as situations when damage and return occur). However, under overload working condition, most couriers could hardly ensure good communications with customers. According to informal statistics, in some private expresses, couriers have more than 100 deliveries each day, which need at least five hours to finish, with each parcel even only costing 3 minutes to be signed for. In view of time-consuming elements like transport process and parcel reception, couriers need to make full use of every minute to fulfill their tasks, so it is normal that they have no time to pay attention to their attitudes. How to improve couriers' service attitude? The fundamental way is to reduce workload of these couriers which on the one hand, needs the reconstruction of salary system in express industry to avoid couriers' excessive pursuit of delivery quantity and on the other, needs the optimization of profits distribution scheme of online supply chain to elevate the status of terminal delivery in distribution process thus completely reversing express industry's ignorance on "the last mile problem".

Service reliability, a basic requirement of online shoppers, had three assessment standards in theoretical models of this paper: the first one was whether deliverers could accurately hand over parcels. The second was whether deliverers could accurately hand over parcels to the destination address. The third was whether deliverers could abide by delivery time commitment. Customers' attention on delivery reliability could be explained from theoretical and practical perspectives. Theoretically speaking, it had already been revealed by many related papers that reliability was the basic dimension of logistics service quality. Practically speaking, it was common to see parcel damages and appointment break recently, so customers' rights and interests were hard to be guaranteed. Therefore, online shoppers had strong expectations on service reliability.

Traditional views attached little importance to the standardization of delivery, however, as revealed by this paper, it was also a key dimension of customer service requirement. Express customers paid special attention to operation like authentication, transport processing and exception handling. Presently, express industry in China generally ignore authentication in delivery which to some extent, increase customers' worry about false claim. Parcel carrying ways affect customers' evaluation on service quality. Therefore, couriers should avoid savage carrying and operate carefully in front of customers.

As indicated before, flexible delivery also constituted a dimension of customer service requirement. It required that the couriers could change delivering time and place according to customers' instructions, which was very difficult to implement in actual operation. Customers hoped couriers could redeliver those unsigned parcels, a service that customers were entitled to enjoy according to national standard of Express Delivery. But in real conditions, in order to save costs, most express companies failed to implement redelivery duty. It was believed in the 
paper that taking flexible delivery as universal requirement would significantly increase the operating costs of express industry which would finally be transferred into customers. Therefore, customers' delivery flexibility requirement should be rationally perceived.

\section{Summary}

From the perspective of customers, the four-dimension measurement model of customer service requirement was presented by taking parcel-delivering process as the goal of this study and combining theoretical analysis with empirical approach, which provided basis to the discussion of improving delivery service management. As indicated by the study, the key of improving parcel delivering management lies in three aspects, namely, service attitude, service reliability and service standardization. This study speculated that consumers had more requirements on delivery process than its result, so process regulation should be strengthened in the last mile of delivery. However, currently, service flexibility should not be enforced because of implementation cost, it is a necessary tradeoff between service level and express enterprise's tolerance.

Two shortcomings existed in this paper: Firstly, the age structure of respondents invited to anonymously answer the online questionnaire was not consistent with that of current online buyers. According to the prediction of "2011 Research Report of Online Shopping Market in China" issued by CNNIC, Taobao's customers born in the 1970 s accounted for $11.1 \%$ but in this study the proportion of the samples was 20.3\%; Users born in the 1980 s accounted for more than $70 \%$ (only the statistical figures of each age group were presented by the report, but the proportion of people born in the 1980s could not be precisely calculated) while the proportion of samples in this paper was $60.7 \%$. It can thus be seen that the average age of respondents was slightly greater, which exerted less clear influence on customer service requirement. Secondly, customers might enforce service requirement of other logistics process on delivery (such as in the evaluation of reliability), the service interface of online shopping supply chain. In this paper, those interference factors were not abandoned purposely, but will be completed in latter studies.

\section{Acknowledgment}

This work was jointly supported by Anhui Provincial Natural Science Foundation (1208085QG138) and funds for special major and pilot project for comprehensive reform of logistics management in Anhui Province. Additionally, thanks for the suggestions given by anonymous reviewers.

\section{References}

Bian, W.L., Ju, S.D., Xu, J. \& Ding, J. Z. (2011). An Empirical Research on Online B2C Customer Perceptions of Logistics Services and Related Factors. Journal of Industrial Engineering /Engineering Management, 25(2), 14-20. 
Bienstock, C.C., Mentzer, J.T. \& Bird, M.M. (1997). Measuring physical distribution service quality. Journal of the Academy Marketing Science, 25(4), 31-44. http://dx.doi.org/10.1007/BF02894507

Cui, L. \& Zhang, H. (2010). The Model on Service Quality, Supplier Customer Relationship and Customer Satisfaction in City Distribution. Journal of Beijing Technology and Business University(Social Science), 25(3), 16-21.

Feng, Y.X., Zheng, B. \& Tan, J.R. (2007). Exploratory study of logistics service quality scale based on online shopping malls. Journal of Zhejiang University Science A, 8(6), 926-931. http://dx.doi.org/10.1631/jzus.2007.A0926

Huang, F. \& Wang, J. (2011). The Empirical Study of logistics Service Quality Evaluation Within Online Shopping in China. Technoeconomics \& Management Research, 32(10), 54-58.

Li, A.G., Peng, Q.Y. \& Huang, J.H. (2007). Exploratory Study on Measurement of Customer Perceived Service Quality in Third Party Logistics(TPL). World Sci-Tech R\&D, 29(3), 87-94.

Lin, J.D. (2009). The Building on Appraising Indexes System of Service Quality Satisfaction for Third-Party Logistics. Value Engineering, 28(6), 84-86.

Liu, M.F., Gong, Y.Z. \& Yang, X. (2006). Study on System of Logistics Service Quality Based on Customer Value. Journal of WUT (Information \& Management Engineering), 28(12), 112-115.

Mentzer, J.T., Gomes, R., \& Krapf, R.E. (1989). Physical Distribution Service: A Fundamental Marketing Concept?. Journal of the Academy of Marketing Science, 17(4), 53-62. http://dx.doi.org/10.1007/BF02726354

Mentzer, J.T., Flint, D.J. \& Kent, J.L. (1999). Developing a logistics service quality scale. Journal of Business Logistics, 20(1), 9-32.

Mentzer, J.T. \& Williams, L.R. (2001). The role of logistics leverage in marketing strategy. Journal of Marketing, 8(3/4), 29-48.

Parasuraman, A., Zeithaml, V.A. \& Berry, L.L. (1988). SERVQUAL: a multiple item scale for measuring consumer perceptions of service quality. Journal of Retailing, 63(49), 12-37.

Stank, T.P., Goldsby. T.G., Vickery, S.K. \& Savitskie, K. (2003). Logistics Service Performance: Estimating Its Influence on Market Share. Journal of Business Logistics, 4(1), 27-56. http://dx.doi.org/10.1002/j.2158-1592.2003.tb00031.x

Tang, G.H. \& Li, Q. (2009). Economics of internet consumption: empirical study on logistics service and customer loyalty. Journal of Quest, 29(3), 8-10. 
Xing, Y. \& Grant, D.B. (2006). Developing a framework for measuring physical distribution service quality of multi-channel and "pure player" internet retailers. International Journal of $\begin{array}{lllll}\text { Retail } \& \quad \text { Distribution } & \text { 278-289. }\end{array}$ http://dx.doi.org/10.1108/09590550610660233

Xu, H.J. (2009). Evaluation of SERVQUAl and customer's satisfaction of logistics service. China Storage and Transport, 11(5), 81-82.

Ye, Z.L., Cai, L., Ye, Z.H. \& Dai, L. (2011). Third party logistics service quality and its impact on customer satisfaction of C2C. Science Research Management, 32(8), 119-126.

Zhang, S. Z. \& Wu, Q. Q. (2007). Logistics service quality and its quantitative analysis. Journal of Chang'an University (Social Science Edition), 9(2), 23-27.

Zhang, Y.L., Xie, G.Y. \& Chen, J. (2013). The Construction of Evaluation Index System of Logistics Service Quality in Online Shopping with Small B2C and C2C as Example. Journal of Anhui Agriculture Science, 41(1): 454-458.

Zheng, B., Dong, D.H. \& Jin, Y.F. (2007). Review of the Foreign Study on Logistics Service Quality. Chinese Journal of Management, 4(3), 373-378.

Zheng, B., Dong, D.H. \& Jin, Y.F. (2008). Research on Antecedents of Customer Satisfaction for the Third Logistics: Customer Based. Journal of Industrial Engineering/Engineering Management, 22(2), 51-57.

Zheng, B., Jin, Y.F., Dong, D.H. \& Liu, R.M. (2007). Founding of Indices of Logistics Service Quality and Empirical Study in China. Management Review, 19(4), 49-55.

Zheng, B. (2008). A Study on Logistics Service Quality and Its Relationship with Customer Loyalty of B2C Internet Store. Dalian: Dalian University of Technology.

Zhou, Z.G. \& Shi, G.H. (2009). Comprehensive Logistics Service Quality Evaluation Based on Fuzzy Theory. Industrial Engineering Journal, 12(5), 72-76.

Journal of Industrial Engineering and Management, 2013 (www.jiem.org)

Article's contents are provided on a Attribution-Non Commercial 3.0 Creative commons license. Readers are allowed to copy, distribute and communicate article's contents, provided the author's and Journal of Industrial Engineering and Management's names are included. It must not be used for commercial purposes. To see the complete license contents, please visit http://creativecommons.org/licenses/by-nc/3.0/. 